\title{
Effect of Addition of Soybean Oil and Gamma-Ray Cross-linking on the Nanoporous HDPE Membrane
}

\author{
Jong-Seok Park, ${ }^{1}$ Jong-Bae Choi, ${ }^{1}$ Hui-Jeong Gwon, ${ }^{1}$ Youn-Mook Lim, ${ }^{1}$ Myung Seob Khil, ${ }^{2}$ \\ Phil-Hyun Kang, ${ }^{1}$ and Young-Chang Nho ${ }^{1}$ \\ ${ }^{1}$ Advanced Radiation Technology Institute, Korea Atomic Energy Research Institute, 1266 Sinjeong-dong, Jeongeup, \\ Jeonbuk 580-185, Republic of Korea \\ ${ }^{2}$ Department of Organic Materials and Fibers Engineering, Chonbuk National University, Jeongju 561-756, Republic of Korea
}

Correspondence should be addressed to Young-Chang Nho, jaspa@hanmail.net

Received 23 February 2012; Accepted 16 April 2012

Academic Editor: Sevan P. Davtyan

Copyright (C) 2012 Jong-Seok Park et al. This is an open access article distributed under the Creative Commons Attribution License, which permits unrestricted use, distribution, and reproduction in any medium, provided the original work is properly cited.

A nanoporous high-density polyethylene (HDPE) membrane was prepared by a wet process. Soybean oil and dibutyl phthalate (DBP) were premixed as codiluents, and gamma-rays were used for the cross-linking of HDPE. The pore volume of the nanoporous HDPE membranes with soybean oil was affected by the extracted amount of oil. The tensile strength of the membrane improved with an increasing absorbed dose up to $60 \mathrm{kGy}$, but decreased at $80 \mathrm{kGy}$ due to severe degradation. The ionic conductivity of the nanoporous HDPE membrane did not really change with an increasing absorbed dose because the pores had already been formed before the gamma-ray radiation. Finally, the electrochemical stability of the HDPE membrane increased when the absorbed dose increased up to $60 \mathrm{kGy}$.

\section{Introduction}

A lithium secondary battery cell is generally comprised of an anode, a cathode, a nonaqueous electrolyte, and a separator, and each component in such a battery cell has been studied thoroughly to achieve the best battery performance $[1,2]$.

A separator is a critical component in lithium secondary batteries, and its main function is to prevent an electrical short circuit, permeate high ions, and be thermally stable and mechanically strong during an assembly operation $[3,4]$.

Nanoporous high-density polyethylene (HDPE) membranes are widely used as separators in Li-ion secondary batteries [5]. HDPE is one of the most important thermoplastics due to its good mechanical properties and resistance to chemicals and harsh environments $[6,7]$.

There are several techniques that are generally used for the fabrication of HDPE membranes, including a dry process, a nonwoven matrix, and a wet process. The dry process is relatively less expensive, and there is no solvent contamination; however, its major disadvantage is a relatively low tear resistance to the machine direction, due to the highly oriented structure $[8,9]$. Nonwoven membranes have some disadvantages, such as a large pore size and thicker nature [5]. The wet process is suitable to achieve high porosity if a stretching step is added. Also, a membrane manufactured through a wet process is nonoriented for both the pore structure and mechanical strength [10-15].

However, these polyolefin membranes have some disadvantages such as a poor compatibility with liquid electrolytes due to their hydrophobic property, and a large thermal shrinkage $[3,4]$. Sufficient data have not yet been reported in the exiting literature for polyolefin membranes, which have a good mechanical property and low thermal shrinkage while maintaining high porosity.

From these backgrounds, we tried to develop a membrane that has a good mechanical property and low thermal shrinkage while maintaining high porosity. The objective of this research is to report the results of a study on the role and effects of gamma-ray irradiation and soybean oil on the properties of a nanoporous HDPE membrane. 


\section{Materials and Methods}

2.1. Materials. A commercial grade high-density polyethylene (HDPE; Hivorex 5200BH) was used throughout this study and was supplied by Honam Petrochemical Corporation (Daejeon, Korea). The alumina was supplied by Buehler Co., Ltd. (Lake Bluff, USA). The particle size and specific surface area of the alumina were $50 \mathrm{~nm}$ and $100.2 \mathrm{~m}^{2} / \mathrm{g}$.

Dibutyl phthalate (DBP) and soybean oil were used as codiluents. DBP was purchased from Junsei chemical Co., Ltd. (Tokyo, Japan). Soybean oil was supplied by SigmaAldrich Co., Ltd. (St. Louis, USA). An electrolyte solution consisting of $1.0 \mathrm{M}$ of $\mathrm{LiClO}_{4}$ in a $1: 1(\mathrm{v} / \mathrm{v})$ ethylene carbonate (EC)/diethyl carbonate (DEC) mixture was donated from Techno-Semichem Corporation (Kongju, Korea) and placed in an Ar-filled glove box. The electrodes $\left(\mathrm{LiCoO}_{2}\right.$ and $\mathrm{MCMB}$ ) used in this study were purchased from the Korea Power Cell Company.

2.2. Sample Preparation. Soybean oil and DBP were premixed as codiluents for the formation of pores. The HDPE pellets and alumina with codiluents were mixed in an extruder (Brabender D-47055) and uniaxially drawn by a roller to obtain precursor films.

The precursor films are irradiated by $\gamma$-ray at a dose rate of $5 \mathrm{kGy} / \mathrm{hr}$. The irradiated films were uni-axially stretched by up to $600 \%$ in a propylene glycol bath at $120^{\circ} \mathrm{C}$ and then extracted by ethanol.

The mixing formulations are shown in Table 1.

2.3. Measurements of the Samples. The porosity and pore diameter of the samples were measured with a mercury porosimeter (AutoPore IV 9500; Micromeritics, USA). Concerning the porosity, at least three specimens were tested, and the average value was taken.

The morphological changes of the samples were observed using a scanning electron microscope (SEM; JSM6390 JEOL Company, Japan). The specimen surfaces were coated with a thin layer of gold palladium alloy by sputtering to provide a conductive surface.

The structural changes of the prepared sample were investigated by FT-IR spectroscopy (Bruker Optik GmbH, Germany).

The tensile strength was measured with an Instron443 at room temperature. The size of the specimens was $5 \times 20 \mathrm{~mm}$, the thickness was about $0.02 \mathrm{~mm}$, and the head speed was $10 \mathrm{~mm} / \mathrm{min}$. The tensile strength of each sample was tested at least five times, and the average value was taken.

A thermal shrinkage test of the sample was conducted in an oven at $120^{\circ} \mathrm{C}$ for $60 \mathrm{~min}$. The thermal shrinkage $\left(S_{h}\right)$ can be calculated by the following equation:

$$
S_{h}(\%)=\frac{\left(A_{\mathrm{o}}-A_{a}\right)}{A_{\mathrm{o}}} \times 100,
$$

where $A_{\mathrm{o}}$ is the original area of the samples before heating, and $A_{a}$ is the area of the samples after heating.

To measure the ionic conductivity, the membranes were soaked in an electrolyte solution at room temperature in an
TABLe 1: Preparation conditions for the HDPE membranes.

\begin{tabular}{lcccc}
\hline $\begin{array}{l}\text { Sample } \\
\text { name }\end{array}$ & HDPE (wt\%) & Alumina (\%) & $\begin{array}{c}\text { Soybean oil } \\
(\text { wt } \%)\end{array}$ & DBP (wt\%) \\
\hline S10 & 74 & 10 & 10 & 6 \\
S14 & 70 & 10 & 14 & 6 \\
S19 & 65 & 10 & 19 & 6 \\
S25 & 59 & 10 & 25 & 6 \\
\hline
\end{tabular}

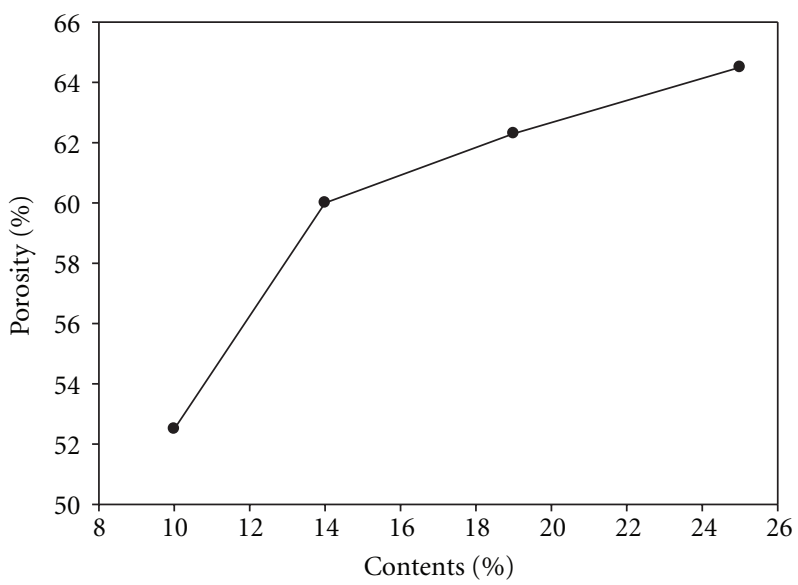

FIGURE 1: The porosity of the nanoporous HDPE membrane with soybean oil content.

Ar-filled glove box and sandwiched between two stainless steel blocking electrodes. The ionic conductivity at room temperature was determined by the $\mathrm{AC}$ impedance technique in a frequency range of 0.01 to $100 \mathrm{kHz}$ using a Solartron SI 1260 frequency response analyzer, which was combined with an SI 1287 electrochemical interface. The constant potential was $10 \mathrm{mV}$. Samples with area $(A)$ and thickness $(L)$ were sandwiched between two stainless steel blocking electrodes to measure the electrolyte resistance $\left(R_{b}, \Omega\right)$. The ionic conductivity $\left(\sigma, S \mathrm{~cm}^{-1}\right)$ was then calculated by the following equation:

$$
\sigma=\frac{L}{\left(R_{b} \times A\right)} .
$$

To measure the linear sweep voltammetry (LSV), the membranes soaked in a liquid electrolyte solution were sandwiched between the lithium metal and stainless steel and assembled into a tightly sealed test cell. The LSV test for the membrane was determined to be from $3.0 \mathrm{~V}$ to $5.5 \mathrm{~V}$ at $0.5 \mathrm{mV} / \mathrm{sec}$.

\section{Results and Discussion}

As its main function, the membrane for a lithium secondary battery should be a very good electronic insulator and has the capability of conducting ions by soaking the electrolytes. Also, they should minimize adverse affects such as serious damage and thermal shrinkage [16-18].

Figure 1 shows the porosity of the nanoporous HDPE membrane with the soybean oil content. The porosity of the 


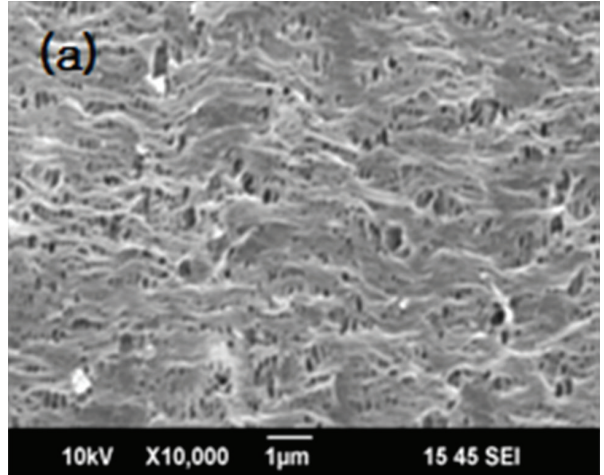

(a)

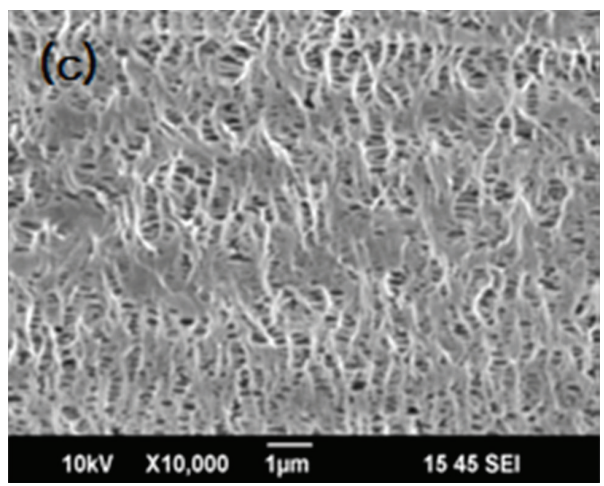

(c)

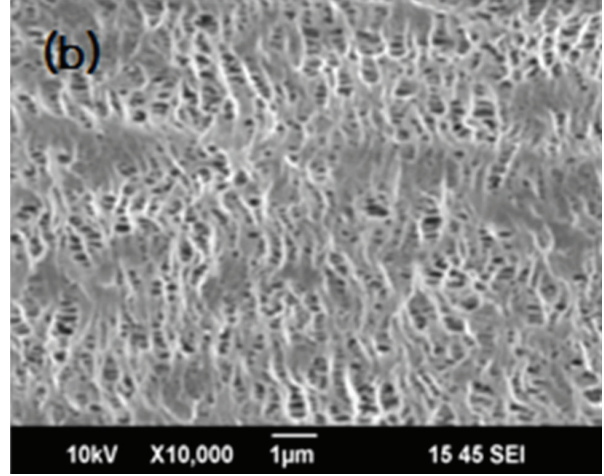

(b)

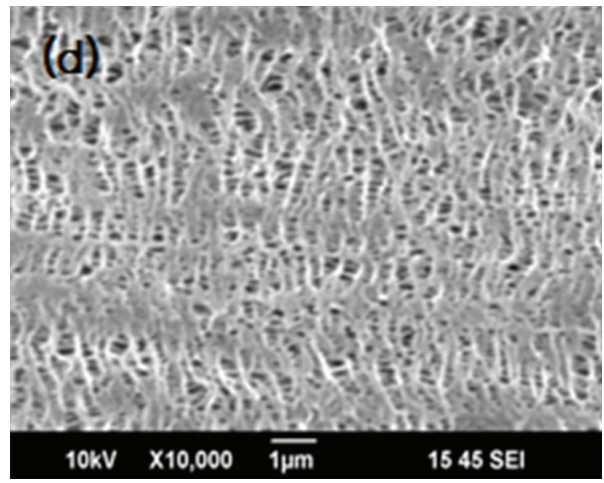

(d)

Figure 2: The SEM micrographs of the surface of the HDPE membrane: (a) S10, (b) S14, (c) S19, and (d) S25.

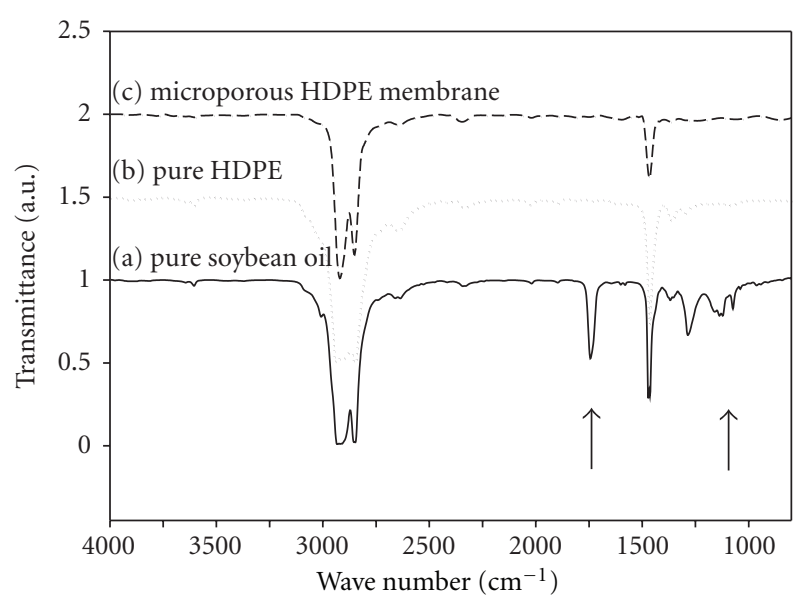

FIgUre 3: The FT-IR spectra of the HDPE membrane with soybean oil.

nanoporous HDPE membrane increased with increasing amounts of soybean oil. The porosity of the HDPE membrane containing soybean oil with $10 \%$ alumina was about $52 \%$ and that of the HDPE membrane containing soybean oil with 25 wt $\%$ was about $64 \%$.

SEM images of the surface of the nanoporous HDPE membrane with soybean oil content are shown in Figure 2. It can be clearly seen that the nanosized pore volume on the
HDPE membranes increased with an increase in soybean oil contents. From this result, it was found that the porosity of the nanoporous HDPE membrane is directly related to the content of soybean oil. The main reason for this result is presented in Figure 3.

Figure 3 shows the FT-IR spectrums as a function of the addition of soybean oil. Figures 3(a) and 3(b) are FT-IR spectrums of pure soybean oil and pure HDPE, respectively. Figure $3(\mathrm{c})$ is the HDPE blend containing 25\% soybean oil after extraction. The FT-IR spectrum of Figure 3(a) showed that a peak corresponding to the $-\mathrm{C}=\mathrm{O}$ stretching vibration peak of the ester group at $1746 \mathrm{~cm}^{-1}$, and the $-\mathrm{C}-$ O stretching vibration peaks at 1255, 1160, and $1120 \mathrm{~cm}^{-1}$, appeared. When the HDPE blend contained 25\% soybean oil after extraction (Figure $3(\mathrm{c})$ ), the $\mathrm{C}=\mathrm{O}$ stretching vibration peak and $-\mathrm{C}-\mathrm{O}$ stretching vibration peaks of the soybean oil had completely disappeared. Also, the FT-IR spectrum of Figure 3(c) is similar to that of pure HDPE (Figure 3(b)).

From these results, it was found that the pore volume of the nanoporous HDPE membranes with soybean oil was affected by the extracted extent of the soybean oil. Consequently, the pore volume of the nanoporous HDPE membranes increased with an increase in the content of the soybean oil.

Figure 4 shows the tensile strength of a nanoporous HDPE membrane with an increase in radiation dose. The tensile strength of the HDPE membrane decreased with an increase in the contents of the soybean oil due to the 


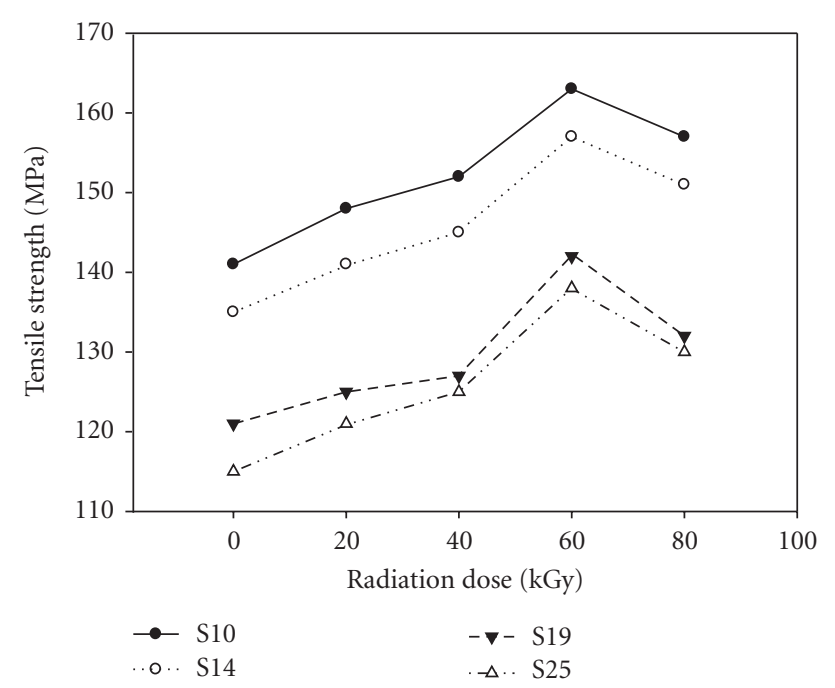

Figure 4: The tensile strength of the nanoporous HDPE membrane with an increasing radiation dose.

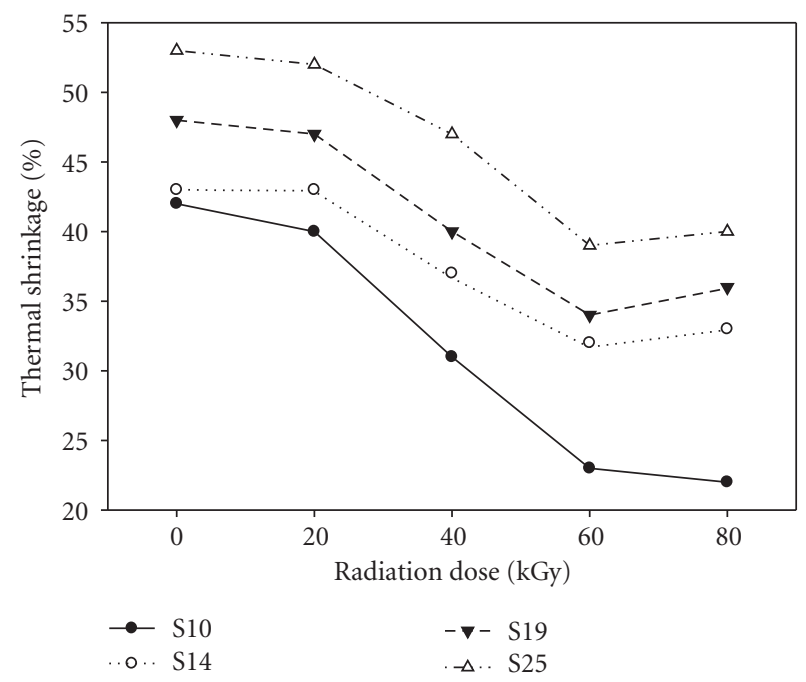

FIgURE 5: The thermal shrinkage of the nanoporous HDPE membrane with an increasing radiation dose.

increased pore volume. However, the tensile strength of the membrane increased with an increase in absorbed dose up to $60 \mathrm{kGy}$, but decreased at $80 \mathrm{kGy}$ due to severe degradation. As shown in Figure 4, the high doses of irradiation induced severe degradation rather than a crosslinking of the materials.

A nanoporous film should be resistant to severe conditions such as high temperature. For example, the thermal shrinkage rate of a nanoporous film should be minimized [4]. Figure 5 shows the thermal shrinkage of the nanoporous HDPE membrane with an increase in radiation dose. As shown in Figure 5, the thermal shrinkage of the nanoporous HDPE membrane decreased with an increase in absorbed dose up to $60 \mathrm{kGy}$ due to the formation of a cross-linked network in the HDPE membrane, which is caused by gamma irradiation. In addition, the thermal shrinkage of the

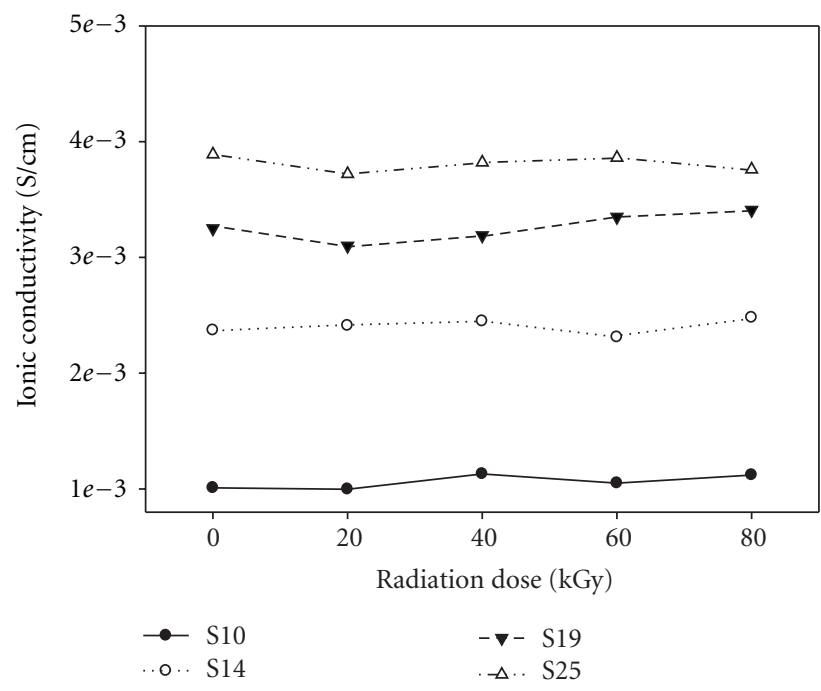

FIgURE 6: The ionic conductivity of the nanoporous HDPE membrane with an increasing radiation dose.

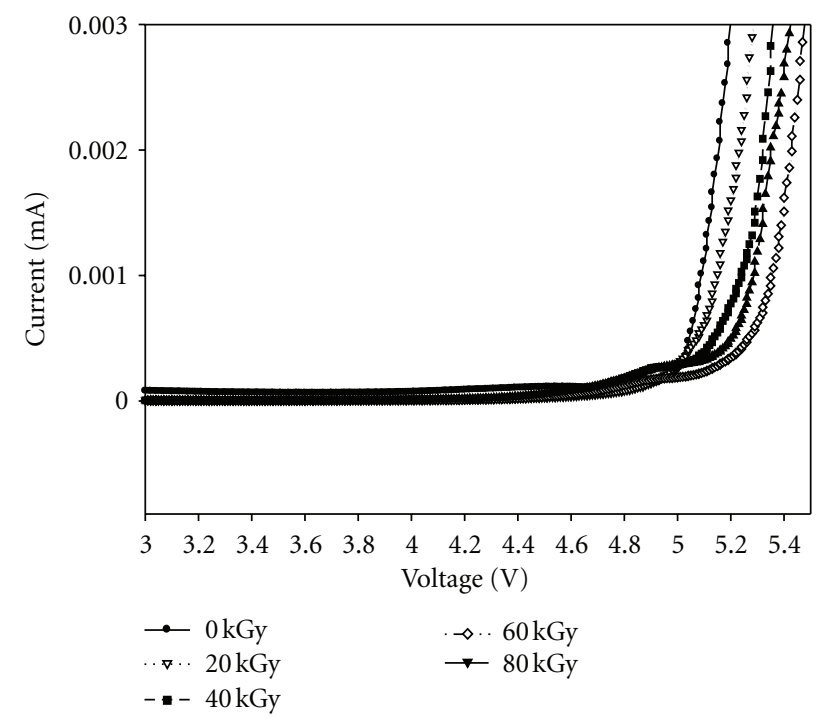

FIGURE 7: The linear sweep voltammetry (LSV) of the nanoporous HDPE membrane with an increasing radiation dose (S19).

nanoporous HDPE membrane with the same absorbed dose increased when the content of the soybean oil was increased due to the shrinkage of the increased pores in the HDPE membrane.

Figure 6 shows the ionic conductivity of the nanoporous HDPE membrane with an increase in radiation dose. The ionic conductivity of the nanoporous HDPE membrane increased with the content of the soybean oil. This result is very similar to the porosity trend of Figure 1 . This can be attributed to the higher porosity and faster transportation of Li-ions through the pores in the HDPE membranes [19]. Also, the ionic conductivity of the nanoporous HDPE membrane did not really change with an increase in absorbed 
dose because the pores had already been formed before $\gamma$-ray radiation.

The electrochemical stability of this novel membrane can be evaluated by linear sweep voltammetry (LSV). Figure 7 shows the LSV of the nanoporous HDPE membrane with an increase in radiation dose. Generally, the current-voltage study of the polymer electrolyte has been employed to determine whether the polymer electrolyte can withstand the operating voltage such as $3-4.2 \mathrm{~V}$ of the battery system. As shown in Figure 7, all of the irradiated HDPE membrane in a test cell shows a good electrochemical stability on the anode up to $5.2 \mathrm{~V}$, while the nonirradiated HDPE membrane shows oxidation stability on the anode up to $5.0 \mathrm{~V}$. The irradiated HDPE membrane, especially at $60 \mathrm{kGy}$, exhibited anodic stabilities of up to 5.4. These results clearly indicate that the irradiated HDPE membrane can withstand electrolyte oxidation on the operating voltage of the battery system.

\section{Conclusion}

The purpose of this paper was to report the results of a study on the role and effects of gamma-ray irradiation and soybean oil on the properties of a nanoporous HDPE membrane.

The pore volume of the nanoporous HDPE membranes with soybean oil was affected by the extracted amount of oil. Consequently, the pore volume and ionic conductivity of the nanoporous HDPE membranes increased when the content of the soybean oil was increased. The tensile strength of the membrane increased with an increase in absorbed dose of up to $60 \mathrm{kGy}$, but decreased at $80 \mathrm{kGy}$ due to severe degradation. Finally, the electrochemical stability of the HDPE membrane increased with an increase in absorbed dose of up to $60 \mathrm{kGy}$.

\section{Acknowledgments}

This work was supported by Nuclear R\&D program through Korea Science and Engineering Foundation funded by the Ministry of Education, Science and Technology, Korea.

\section{References}

[1] Y. M. Lee, J. W. Kim, N. S. Choi, J. A. Lee, W. H. Seol, and J. K. Park, "Novel porous separator based on PVdF and PE nonwoven matrix for rechargeable lithium batteries," Journal of Power Sources, vol. 139, no. 1-2, pp. 235-241, 2005.

[2] D. Takemura, S. Aihara, K. Hamano et al., "A powder particle size effect on ceramic powder based separator for lithium rechargeable battery," Journal of Power Sources, vol. 146, no. 1-2, pp. 779-783, 2005.

[3] D. W. Ihm, J. G. Noh, and J. Kim, "Effect of polymer blending and drawing conditions on properties of polyethylene separator prepared for Li-ion secondary battery," Journal of Power Sources, vol. 109, no. 2, pp. 388-393, 2002.

[4] S. S. Zhang, "A review on the separators of liquid electrolyte Li-ion batteries," Journal of Power Sources, vol. 164, no. 1, pp. 351-364, 2007.

[5] S. M. Kwon, K. J. Kim, H. Kim et al., "Tensile property and interfacial dewetting in the calcite filled HDPE, LDPE, and
LLDPE composites," Polymer, vol. 43, no. 25, pp. 6901-6909, 2002.

[6] F. Sadeghi, A. Ajji, and P. J. Carreau, "Analysis of microporous membranes obtained from polypropylene films by stretching," Journal of Membrane Science, vol. 292, no. 1-2, pp. 62-71, 2007.

[7] P. P. Prosini, P. Villano, and M. Carewska, "A novel intrinsically porous separator for self-standing lithium-ion batteries," Electrochimica Acta, vol. 48, no. 3, pp. 227-233, 2002.

[8] J. S. Park, S. J. Gwon, Y. M. Lim, and Y. C. Nho, "Effects of a radiation crosslinking on a drawn microporous HDPE film with a nucleating agent," Macromolecular Research, vol. 17, no. 8, pp. 580-584, 2009.

[9] J. A. Morehouse, L. S. Worrel, D. L. Taylor, D. R. Lloyd, B. D. Freeman, and D. F. Lawler, "The effect of uni-axial orientation on macroporous membrane structure," Journal of Porous Materials, vol. 13, no. 1, pp. 61-72, 2006.

[10] M. Y. Jeon and C. K. Kim, "Phase behavior of polymer/diluent/ diluent mixtures and their application to control microporous membrane structure," Journal of Membrane Science, vol. 300, no. 1-2, pp. 172-181, 2007.

[11] H. A. Khonakdar, J. U. Morshedian, U. Wagenknecht, and S. H. Jafari, "An investigation of chemical crosslinking effect on properties of high-density polyethylene," Polymer, vol. 44, no. 15, pp. 4301-4309, 2003.

[12] D. K. Lee, J. T. Park, J. K. Choi et al., "Proton conducting crosslinked membranes by polymer blending of triblock copolymer and poly(vinyl alcohol)," Macromolecular Research, vol. 16, no. 6, pp. 549-554, 2008.

[13] B. Luo, J. Zhang, X. Wang, Y. Zhou, and J. Wen, "Effects of nucleating agents and extractants on the structure of polypropylene microporous membranes via thermally induced phase separation," Desalination, vol. 192, no. 1-3, pp. 142-150, 2006.

[14] M. J. Weighall, "Effects of nucleating agents and extractants on the structure of polypropylene microporous membranes via thermally induced phase separation," Journal of Power Sources, vol. 34, no. 3, pp. 257-268, 1991.

[15] S. S. Zhang, K. Xu, and T. R. Jow, "An inorganic composite membrane as the separator of Li-ion batteries," Journal of Power Sources, vol. 140, no. 2, pp. 361-364, 2005.

[16] H. Matsuyama, M. M. Kim, and D. R. Lloyd, "Effect of extraction and drying on the structure of microporous polyethylene membranes prepared via thermally induced phase separation," Journal of Membrane Science, vol. 204, no. 1-2, pp. 413-419, 2002.

[17] H. J. Park, S. C. Hong, and S. Y. Lee, "Effect of microporous structure on thermal shrinkage and electrochemical performance of $\mathrm{Al}_{2} \mathrm{O}_{3} /$ poly(vinylidene fluoride-hexafluoropropylene) composite separators for lithium-ion batteries," Journal of Membrane Science, vol. 364, no. 1-2, pp. 177-182, 2010.

[18] B. Topuz and M. Çiftçioğlu, "Preparation of particulate/ polymeric sol-gel derived microporous silica membranes and determination of their gas permeation properties," Journal of Membrane Science, vol. 350, no. 1-2, pp. 42-52, 2010.

[19] S. J. Gwon, J. H. Choi, J. Y. Sohn, Y. E. Ihm, and Y. C. Nho, "Preparation of a new micro-porous poly(methyl methacrylate)-grafted polyethylene separator for high performance Li secondary battery," Nuclear Instruments and Methods in Physics Research B, vol. 267, no. 19, pp. 3309-3313, 2009. 

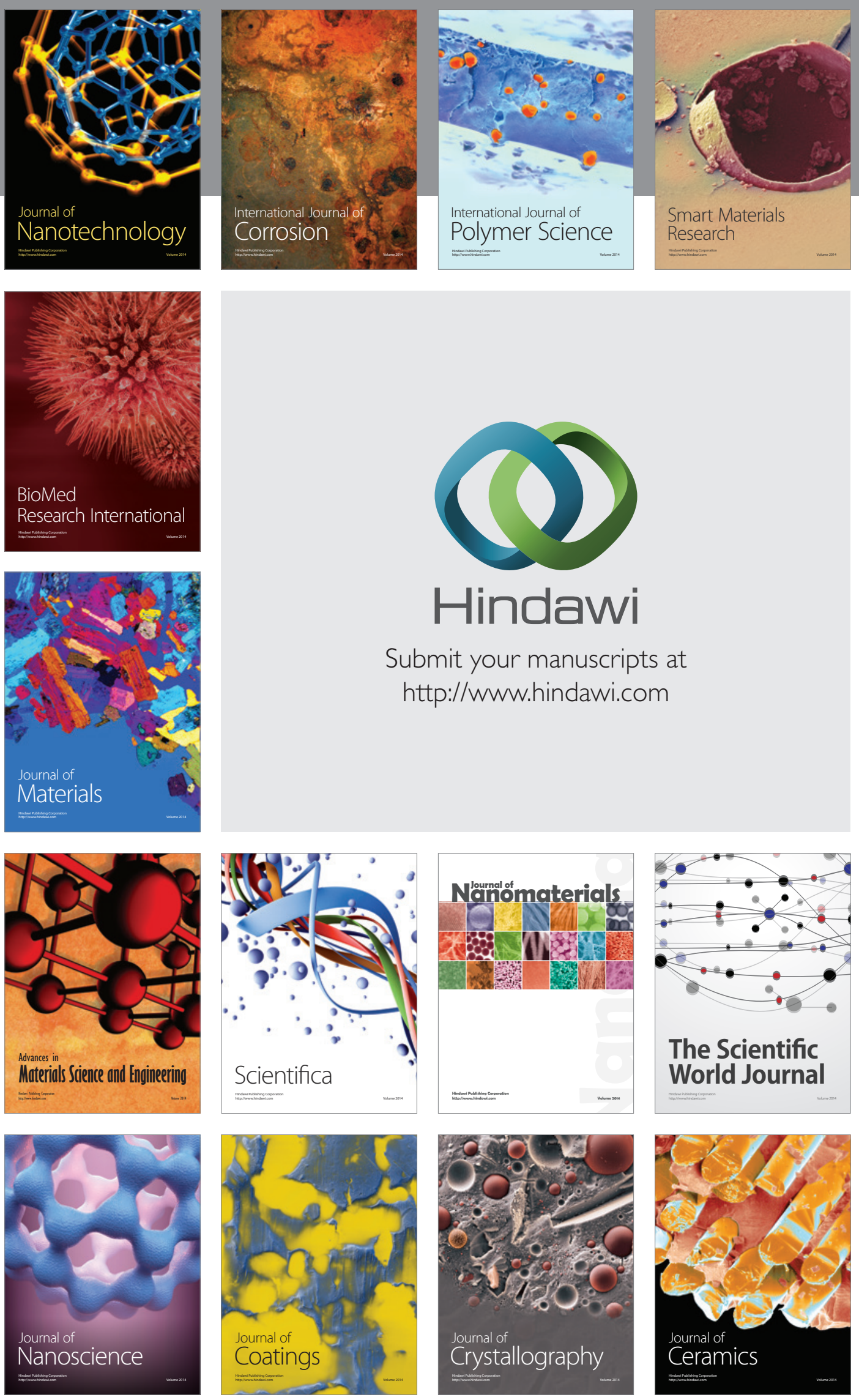

The Scientific World Journal

Submit your manuscripts at

http://www.hindawi.com

\section{World Journal}

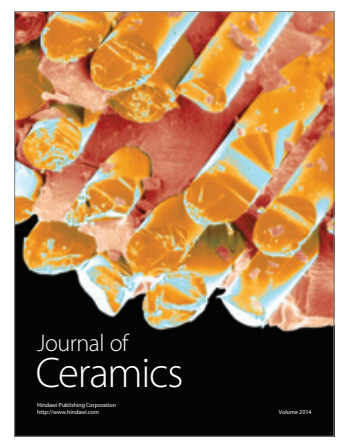

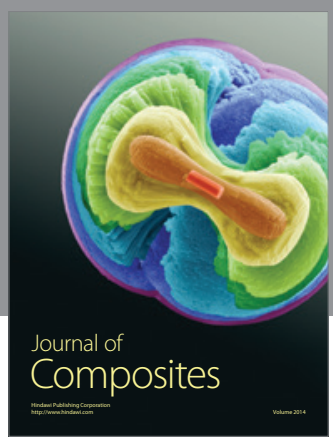
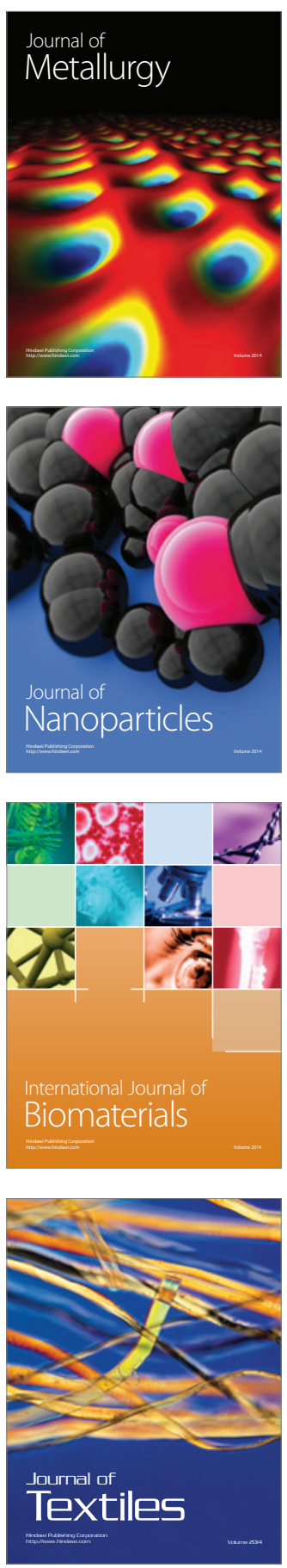